Table 1. Results of Plastochron Determination In Ranunculus hirtus B. AND S. AFTER LABELIING THE YOUNG PRIMORdia WITH

Time interval Carbon-14 DIOXIDE

67 days

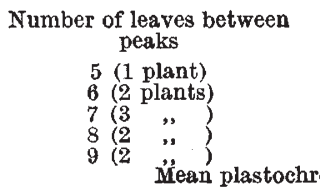

1'lastochron in days

M̈ean plastochron $9 \cdot 6$ s.e. $0 \cdot 59$

$15^{\circ} \mathrm{C}$. The second administration of ${ }^{14} \mathrm{CO}_{2}$ was made after 67 days, a further 43 days being allowed to elapse before contact autoradiographs were prepared (Table 1). Under these conditions the niean plastochron was found to be a little less than 10 days.

Department of Plant Biology,

$$
\text { F. J. F. FrSHER }
$$

Carnegie Institution of Washington, Stanford, California.

Aug. 20.

\section{Chasmogamous Flowering in Viola palustris $\mathbf{L}$.}

AfTER a short burst of chasmogamous flowering in early spring, plants of $V$. palustris, like those of many other violet species, produce a succession of cleistogamous flowers throughout the summer. Such a change in flowering habit could be associated with changes in day-length, as in $V$. fimbriatula and $V$. papilionacea with which Allard and Garner ${ }^{1}$ obtained chasmogamous flowers only in short days and cleistogamous flowers in long days. With several other violet species Chouard ${ }^{2}$ has obtained chasmogamous flowering only in short day-lengths (for example, $V$. odorata), or after exposure to winter temperatures (for example, $V$. silvestris), or after both winter temperatures and subsequent short-day treatment (for example, V. hirta).

Experiments carried out in the Farhart Laboratory at Pasadena on members of five clones of $V$. palustris gave results that may be summarized as follows. Flower initiation may occur in plants under both short ( $8 \mathrm{hr}$.$) and long (16 hr.) photoperiods, and also$ in continuous light. Plants kept in long days at a phototemperature of $20^{\circ} \mathrm{C}$. and nyctotemperature of $14^{\circ} \mathrm{C}$. $\left(20^{\circ} / 14^{\circ} \mathrm{C}\right.$.) produced an abundance of large long-petioled leaves and of even taller peduncles bearing cleistogamous flowers, but never any chasmogamous ones. Plants transferred from long to short days continued to produce cleistogamous flowers for about two weeks : most of them then ceased flowering altogether, although a few plants later bore an occasional chasmogamous flower.

In short days the leaves were much smaller, round rather than cordate, and with short petioles; at $20^{\circ} / 14^{\circ} \mathrm{C}$. most of the initiated flower buds did not develop, but nearly all plants produced occasional chasmogamous flowers, never any cleistogamous ones. In short days at higher temperatures no flowers of either kind were obtained, nor any at $17^{\circ} / 10^{\circ} \mathrm{C}$. Several of the plants transferred from short days produced a few chasmogamous flowers when first moved to long days at $20^{\circ} / 14^{\circ} \mathrm{C}$. before cleistogamous flowering began.

All the plants vermalized for eight weeks at $4^{\circ} \mathrm{C}$. in short days of artificial illumination at 400 footcandles intensity gave a short burst of chasmogamous flowering when transferred to $20^{\circ} / 14^{\circ} \mathrm{C}$. in either short or long photoperiods. In long days this initial burst was followed by continuous cleistogamous flowering, in short days by no further flowering.

These results suggest a certain equivalence between short day-lengths and low temperatures in their en. couragement of chasmogarnous flowering in $V$. palus. tris, as also in the flowering of winter rye ${ }^{3}$, and Chouard's results indicate that in some species the vernalization pathway, in others the short-day path, is the more effective, while in $V$. hirta the joint action of both is usually required. Allard and Garner considered that chasmogamy occurred only in conditions of reduced vegetative expression, which may account for the complete absence of chasmogamous flowers in short days at temperatures above $20^{\circ} / 14^{\circ} \mathrm{C}$. where growth was more abundant. On the other hand, the fact that cleistogamous flowering was also absent in these conditions indicates clearly that the flowering habit is not simply an expression of the amount of growth made. Bergdolt found that chasmogamous flowering of several violet species was favoured by a high nutrient supply; but in the present experiment all plants received a balanced nutrient solution every day, yet only cleistogamous flowers appeared in the continuous long-day treat. ments. Thus the effect of photoperiod on the type of flowering does seem to be specific, and not merely an indirect growth effect. However, the effect of vernalization and short-day treatments on the induc. tion of chasmogamous flowering in $V$. palustris is strikingly ephemeral, few of the buds present during these treatments giving rise to chasmogamous flowers, which does suggest that the specific effects of short days and low temperatures on full flower development may be expressed only within a narrow range of growth conditions.

Division of Plant Industry,

L. T. Evans

Council for Scientific and Industrial Research, Camberra.

Sept. 20.

1 Allard, H. A., and Garner, W. W., U.S. Dept. Agric. Tech. Bull. 727 (1940).

Chouard, P., C.R. Acad. Sci., Paris, 226, 1831 (1948).

Purvis, O. N., and Gregory, F. G., Ann. Bot., N.S., I, 569 (1937).

- Bergdolt, E., Bot. Abh., 20, 42 (1932).

\section{Control of Watercress Crook Root Disease by Zinc-fritted Glass}

Сrоoк root disease of watercress (Nasturtium officinale, R.Br. and $N$. officinale $\times N$. microphyllum, Boenn. ex Rchb.) was first reported in 1948 by officers of the National Agricultural Advisory Service. During 1949 the disease was found in all the watercress-growing districts, and it has now reached such serious proportions that it is a major threat to the industry.

The disease was found by Spencer and Glasscock ${ }^{\mathrm{t}}$ to be caused by a water-borne fungus (probably a species of Spongospora) which infects the roots and causes them to become swollen, distorted and 'crooked'. Infected plants lose vigour, become stunted and may eventually die. Investigations, since made by me, indicate that a practical control of the disease may be obtained by the addition of traces of zinc to the water in the watercress bed.

Laboratory studies on the disease were made by growing healthy rooted watercress cuttings in distilled water in glass jars together with watercress cuttings 